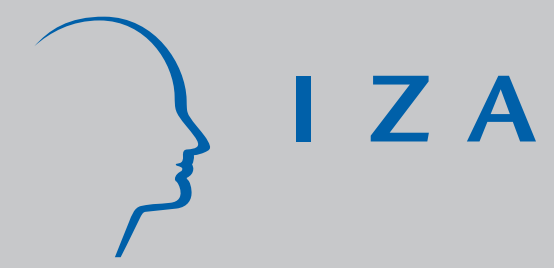

IZA DP No. 771

J ob Matching, Social Network and Word-of-Mouth Communication

Antoni Calvó-Armengol

Yves Zenou

May 2003 


\title{
Job Matching, Social Network and Word-of-Mouth Communication
}

\author{
Antoni Calvó-Armengol \\ Universidad Carlos III de Madrid \\ Yves Zenou \\ University of Southampton, GAINS, \\ CEPR and IZA Bonn
}

\author{
Discussion Paper No. 771 \\ May 2003
}

\author{
IZA \\ P.O. Box 7240 \\ D-53072 Bonn \\ Germany \\ Tel.: +49-228-3894-0 \\ Fax: +49-228-3894-210 \\ Email: iza@iza.org
}

\begin{abstract}
This Discussion Paper is issued within the framework of IZA's research area The Future of Labor. Any opinions expressed here are those of the author(s) and not those of the institute. Research disseminated by IZA may include views on policy, but the institute itself takes no institutional policy positions.
\end{abstract}

The Institute for the Study of Labor (IZA) in Bonn is a local and virtual international research center and a place of communication between science, politics and business. IZA is an independent, nonprofit limited liability company (Gesellschaft mit beschränkter Haftung) supported by the Deutsche Post AG. The center is associated with the University of Bonn and offers a stimulating research environment through its research networks, research support, and visitors and doctoral programs. IZA engages in (i) original and internationally competitive research in all fields of labor economics, (ii) development of policy concepts, and (iii) dissemination of research results and concepts to the interested public. The current research program deals with (1) mobility and flexibility of labor, (2) internationalization of labor markets, (3) welfare state and labor market, (4) labor markets in transition countries, (5) the future of labor, (6) evaluation of labor market policies and projects and (7) general labor economics.

IZA Discussion Papers often represent preliminary work and are circulated to encourage discussion. Citation of such a paper should account for its provisional character. A revised version may be available on the IZA website (www.iza.org) or directly from the author. 


\section{ABSTRACT \\ Job Matching, Social Network and Word-of-Mouth Communication*}

Workers are embedded within a network of social relationships and can communicate through word-of-mouth. They can find a job either directly or through personal contacts. From this micro scenario, we derive an aggregate matching function that has the standard properties but fails to be homogeneous of degree one because of coordination failures between workers. We show that, when the network size increases, on average, the unemployed workers hear about more vacancies through their social network but, at the same time, it is more likely that multiple vacancies reach the same unemployed worker. Above a certain critical value, this job overcrowding becomes so important that job matches decrease with network size. We then establish existence and uniqueness of the labor market equilibrium and study its properties. In dense enough networks, the equilibrium unemployment rate increases with network size whereas the latter has an ambiguous effect on wages. Finally, we demonstrate that the decentralized market equilibrium is not efficient because of both search and network externalities.

JEL Classification: D83, J64

Keywords: coordination failures, social network, personal communication

Corresponding author:

Yves Zenou

Department of Economics

University of Southampton

Southampton SO17 1BJ

United Kingdom

Email: yz@soton.ac.uk

\footnotetext{
* Part of this work was written while the first author was visiting the University of Southampton and the second author Universidad Carlos III, whose hospitalities are gratefully acknowledged. We would also like to thank the seminar participants at Queen Mary College (London), the Education and Employment Economics Group Annual Conference, the Institute for International Economics Studies (Stockholm). We also gratefully acknowledge the financial support of Spain's Ministry of Education under grant SEC2001-0973. The usual disclaimer applies.
} 


\section{Introduction}

Individuals seeking for jobs read newspapers, go to employment agencies, browse in the web and mobilize their local networks of friends and relatives. Although underestimated by the bulk of the search and matching literature, personal contacts often play a prominent role in matching jobseekers with vacancies. The empirical evidences indeed suggest that about half of all jobs are filled through contacts. ${ }^{1}$ Networks of personal contacts mediate employment opportunities which flow through word-of-mouth and, in many cases, constitute a valid alternative source of employment information to more formal methods. ${ }^{2}$

The aim of this paper is threefold. First, we develop a micro scenario for the matching function in which finding a job depends both on social contacts and informal methods. According to this scenario, workers are linked to each other by a social network, the members of this network can communicate through word-of-mouth and agents partly rely on friends to gather information about employment opportunities. Second, we analyze the relationship between network size and job matches. This relationship is non-monotonic because in larger networks, on average, unemployed workers hear about more vacancies through their social network but coordination failures also increase. Finally, we fully characterize the steady-state labor market equilibrium, establish existence, uniqueness, examine its welfare properties, and investigate the link between the network of personal contacts, the information transmission protocol and the equilibrium unemployment, vacancy and wage rates.

There have been several attempts to find a micro scenario of the standard macroeconomic matching function. The most popular reduced form is the exponential matching function that was first employed by Butters (1977) to model contacts between buyers and sellers in commodity markets. ${ }^{3}$ More recently, Lagos (2000) has proposed an alternative micro approach by deriving an

\footnotetext{
${ }^{1}$ Sociologists and labor economists have produced a broad empirical literature on labor market networks. In fact, the pervasiveness of social networks and their relative effectiveness varies with the social group considered. For instance, Holzer (1988) shows that among 16-23 years old workers who reported job acceptance, $66 \%$ used informal search channels (30\% direct application without referral and $36 \%$ friends/relatives), while only $11 \%$ use state agencies and 10\% newspapers. See also Corcoran et al. (1980) and Granovetter (1995). More recently, Topa (2001) argues that the observed spatial distribution of unemployment in Chicago is consistent with a model of local interactions and information spillovers, and may thus be generated by agent's reliance in informal methods of job search such as networks of personal contacts.

${ }^{2}$ Montgomery (1991) emphasizes the role of networks and its advantages for the employer relative to other channels as providing a screening device against low-ability workers. Indeed, it is widely documented that individuals tend to interact with individuals like themselves (a property often called assortative matching or inbreeding bias). Therefore, currently employed high-ability workers (whose type has already been revealed to the employer) are more likely to refer workers of the same type. Because of that, employers often delegate to the network of their current workforce the screening function of finding a suitable employee. Our focus here is rather on characterizing the (endogenous) returns of job information exchange in social networks and the associated labor market equilibrium.

${ }^{3}$ This matching function owes its origin to the well-known and extensively analysed urn-ball model in probability theory. According to this model, the labor market is visualized as 'urns' (vacancies) to be filled by 'balls' (workers).
} 
aggregate matching function which takes the form of a min function. Our micro scenario based on word-of-mouth communication gives insights on the relationship between job search, job matching and social network. In fact, there have been few theoretical attempts to model this link. Notable exceptions include Diamond (1981), Montgomery (1991, 1992) and Mortensen and Vishwanath (1994) that contribute to the theoretical literature on equilibrium wage determination in search markets. However, in all these approaches, the modelling of the social network is quite shallow. To our knowledge, the first paper to explicitly model the structure of social contacts by an undirected network in a labor market context is Boorman (1975). ${ }^{4}$ Following this early contribution, CalvóArmengol (2001) develops a model specifying at the individual level both the decision to establish or to maintain social ties with other agents, and the process by which information about jobs is obtained and transmitted. The analysis focuses on the impact that an endogenous determination of job contact networks has on the effectiveness of information transmission and on the aggregate unemployment level. On the contrary, the present paper builds an aggregate matching function stemming from an explicit network structure, and determines the impact a partial reliance on social networks as a method of job search has on labor market outcomes.

More precisely, in our micro scenario, the structure of personal contacts and the job information transmission process is spelled out in detail. Our model can be seen as an extension of the standard urn-ball model mentioned above. However, in our framework, because of the two ways of finding a job, the network of personal contacts allows for a (partial) replacement of redundant jobs, thus reducing coordination failures and alleviating matching frictions, whose intensity is now explicitly related to network size. We show that our matching function is increasing and strictly concave in both the unemployment and the vacancy rate.

Our second result is to show that the relationship between network structure (namely size) and job finding is not as straightforward as it is commonly viewed. Indeed, in the standard social network literature (especially in sociology), more contacts are thought to be an advantage because of more network members who can potentially broker job vacancies and job seekers. We show in fact that this result crucially depends on the size of the network. Indeed, in a symmetric social network, we demonstrate that, when the network size increases, on average, the unemployed workers hear about more vacancies through their social network but, at the same time, it is more likely

Because of a coordination failure inherent to any random placing of the balls in the urns, not all pairs are matched exactly. Rather, this uncoordinated process yields an overcrowding in some jobs and no applications in others. Such coordination failures are thus the sources of search frictions. In most cases, the system steady state can be approximated by an exponential-type matching function as the population becomes large. See for instance Hall (1979), Pissarides (1979), Peters (1991), Blanchard and Diamond (1994), Burdett, Shi and Wright (2001), Smith and Zenou (2003).

${ }^{4} \mathrm{~A}$ recent and growing literature stresses the role of networks in explaining a wide range of economic phenomema among which labor markets are just an example. See for instance Jackson and Wolinsky (1996), Bala and Goyal (2000) and the references therein. For a previous model of word-of-mouth communication, see Ellison and Fudenberg (1995) and Bala and Goyal (1998). 
that multiple vacancies reach the same unemployed worker, thus increasing coordination failures. Therefore, there exists a critical network size, above which coordination failures are so important that the individual job-acquisition rate decreases. As a result, there is a non-monotonic relationship between network size and the rate at which matches occur so that the matching function fails to be homogenous of degree one.

Our last result is, using this matching function, to fully characterize the steady-state labor market equilibrium whose existence and uniqueness are established. We show that the resulting equilibrium unemployment rate decreases with the network size in sparse networks while it increases when the pattern of links is dense. We also show that the decentralized market equilibrium is not efficient because of both search and network externalities.

\section{The model}

\subsection{The labor market}

We consider a continuum of ex ante identical workers (same education, same skill, same age,...) of mass $n$. There is also a continuum of ex ante identical firms (same wages, same type of jobs,...). Firms do not use national employment agencies to advertize their jobs but rather use local informal methods such as help-wanted signs on their windows or ads in local newspapers. Workers who walk throughout the city or read local newspapers discover at random the information about vacancies. If the worker is unemployed, he takes the job (direct method). If he is employed, we assume that he transmits this information within his social network. Therefore, unemployed workers can obtain a job either indirectly through their employed friends (who have heard about a vacant job) or directly.

\section{Worker's productivity}

We make two important assumptions. First, an employed worker who has heard about a job vacancy can hold this information only for the current period. This if for instance the case if at the beginning of each period the firm must decide to re-open or not the corresponding vacancy, when unfilled. Second, newly employed workers are assumed to go through a one-period probation during which their productivity amounts to $y_{0}$. Without loss of generality, we normalize $y_{0}$ to zero so that this probation period can be viewed as a learning stage in which the worker does not produce but learn the different aspects of the firm. Since the worker does not produce, we assume that during this probation period, the corresponding wage $w_{0}$ is equal to the unemployment benefit $b$, that is, $w_{0}=b$. Without loss of generality, we normalize $b$ to zero. When the one-period probation is completed, the individual productivity jumps to $y_{1}>0$ and stays for ever at this productivity level until he loses his job and becomes unemployed. When this worker finds again a job, he starts again at $y_{0}=0$ for one period and then produces $y_{1}$. And so on. The aim of this learning process is to capture the fact that workers need some firm-specific (human capital) investment to reach a higher 
productivity level.

These two assumptions together imply that an employed worker who has heard about a vacant job will always transmit this information to some unemployed worker. Indeed, given that vacancies are only posted for one period, no employed worker aware of some available job would hold the corresponding offer for himself in case of future adverse contingencies. Furthermore, because of the second assumption, no employed worker can use a job offer to increase his current wage since new jobs always require a probation period paid at a wage $w_{0}=0$.

\section{Timing}

Time is discrete and continues forever. At each point in time, each of the $n$ workers is either employed or unemployed. The timing of the model is as follows. At the end of period $t-1$, the unemployment and employment rates are respectively equal to $u_{t-1}$ and $1-u_{t-1}$. Period $t$ begins with these employment and unemployment rates. At the beginning of period $t, V_{t}$ vacancies are posted. We refer to $v_{t}=V_{t} / n$ as the job arrival rate or the vacancy rate. We assume throughout that $V_{t}<n$. Each worker, either employed or unemployed, directly hear of a vacant job with individual probability $v_{t}$. Job information is then disseminating among workers and jobs are filled according to the procedure described in section 2.2. Denote by $h\left(u_{t-1}, v_{t}\right)$ the individual hiring probability of an unemployed worker. The resulting employment rate after this job filling process is $1-u_{t-1}+u_{t-1} h\left(u_{t-1}, v_{t}\right)$, where $u_{t-1} h\left(u_{t-1}, v_{t}\right)$ have been newly employed whereas $1-u_{t-1}$ are longterm employed (they have been holding the same position for at least one full period). All employed workers immediately start to work. The newly-employed workers produce $y_{0}=0$ units of output during period $t$ and earn $w_{0}=b=0$. Long-term employed workers produce $y_{1}$ and earn a wage $w_{1}$. The wage setting procedure is described in section 4.2. At the end of period $t$, there is a technological shock and employed workers lose their jobs with probability $\delta$. This process is taken to only depend on the general state of the economy and hence is treated as exogenous to the labor market. After this shock, the rate of employed workers is $1-u_{t}=(1-\delta)\left[1-u_{t-1}+u_{t-1} h\left(u_{t-1}, v_{t}\right)\right]$, and the unemployment rate is $u_{t}$. Period $t+1$ then begins with those employment and unemployment rates. And so on.

\subsection{Word-of-mouth information transmission}

In our model, individuals are not isolated one with respect to the other. Rather, they are embedded within a network of social relationships. We assume that, at each period, each worker is in direct contact with a group of $s$ workers. Within each pair of connected workers, information can be transmitted through word-of-mouth communication. We refer to $s$ as the network size.

Let us be more precise about the information transmission. At the beginning of each period, each worker draws his $s$ social contacts at random among the total population of workers. This random draw corresponds for instance to casual encounters. This implies that, on average, at each period, each worker thus meets us unemployed workers and $(1-u) s$ employed workers. Consider 
one currently employed worker who is aware of some job slot available for the current time period. Then, this informed and employed worker passes the job information on to any of the us unemployed acquaintances he meets during the current period. The firm who has posted the vacancy then treats all these unemployed applicants on an equal footing, who all have the same probability to obtain the job.

Observe that, according to this information transmission protocol, job information can only flow through word-of-mouth from an employed to an unemployed worker that is, between workers with different employment status. This information transmission protocol does not preclude the fact that an unemployed worker hears of two or more vacancies from two or more employed acquaintances. When this is so, we assume that the informed unemployed applies for only one job randomly selected. ${ }^{5}$

So the diffusion of information about jobs is here a process in the course of which information is being passed on by those who possess it to those who do not possess it. The process of information diffusion information takes the form of people receiving it from other people in the course of social contacts they make with them. As stated above, some of the social contacts are wasted because they are made with people who do not need this information.

This word-of-mouth sampling generated information is similar to the one used by Ellison and Fudenberg (1995). Their paper analyses technology choices in a stochastic environment. Individual choices are based upon information obtained by asking $s$ other individuals chosen at random from the population about their current choice and payoff. In our model, the individual who samples (the employed and informed) does not receive the information but instead transmits it to the $s$ workers chosen at random from the total population (in fact, to only those that may need it, namely, the us unemployed workers). ${ }^{6}$

\subsection{Finding a job through personal contacts}

We now derive the individual probability of finding a job through social contacts. This probability, denoted by $P(s, u, v)$, depends on the current labor market conditions $(u, v)$ and on the ongoing information transmission process, captured by $s$. We have

$$
P(s, u, v)=1-\left[1-\frac{\tau(s, u, v)}{s}\right]^{s}
$$

where

$$
\tau(s, u, v)=v(1-u) \frac{1-(1-u)^{s}}{u} .
$$

\footnotetext{
${ }^{5} \mathrm{~A}$ more realistic model should also allow for job information exchange among unemployed workers with a common employed friend, whenever they are directly linked with each other. Such generalizations jeopardize the model tractability without adding further insights.

${ }^{6}$ Bala and Goyal (1998) also derive a similar framework in which agents use their own past experience as well as the experience of their contacts to guide their decision making.
} 
The explanation for this result is the following. Fix an unemployed worker $i$ and consider some other worker $j$ in direct contact with $i$ for the time being. Worker $j$ is employed and aware of a redundant job offer with probability $v(1-u)$. Redundant job information is transmitted to unemployed contacts. Worker $i$ is the selected recipient for this information with probability:

$$
\sum_{k=0}^{s-1}\left(\begin{array}{c}
s-1 \\
k
\end{array}\right) \frac{1}{k+1}(1-u)^{s-k-1} u^{k}=\frac{1-(1-u)^{s}}{u s}
$$

Indeed, a random draw of $s$ social contacts by worker $j$ contains $0 \leq k \leq s-1$ additional unemployed workers, besides from $i$, with probability $\left(\begin{array}{c}s-1 \\ k\end{array}\right)(1-u)^{s-k-1} u^{k}$. The job information vacancy held by $j$ is then assigned to any of these $k+1$ unemployed with uniform probability, and worker $i$ receives such information with conditional probability $1 /(k+1)$. Therefore, $\tau(s, u, v) / s$ is the probability of worker $i$ finding a job thanks to his direct contact $j$, which implies (1). Finding a job through word-of-mouth is thus a random experiment consisting of $s$ repeated independent Bernoulli trials with a probability of success at each individual trial given by $\tau(s, u, v) / s$. We have the following result: ${ }^{7}$

Proposition 1 The properties of $P(s, u, v)$ are the following:

(i) $P(\cdot, u, v)$ increases on $[0, \bar{s}]$ and decreases on $[\bar{s}, n]$, where $\bar{s}$ is the unique global maximum of $P(\cdot, u, v)$. Also, $P(\cdot, u, v)$ is strictly concave on $[0, K)$, for some $K>\bar{s}$;

(ii) $P(s, \cdot, v)$ is decreasing in $u$. Also, $P(s, \cdot, v)$ is strictly convex on $[\widetilde{u}, 1]$ for some $0 \leq \widetilde{u}<1 ; 8$

(iii) $P(s, u, \cdot)$ is increasing and strictly concave in $v$.

Therefore, the individual probability of finding a job through word-of-mouth exhibits diminishing marginal returns to network size $s .{ }^{9}$ To understand this result, observe that increasing the network size $s$ has both a (positive) direct and (negative) indirect effect. On one hand, rising the network size expands the available direct connections to every worker at every time period. Workers become better connected and, consequently, the potential job information they can benefit from increases. On the other hand, rising the network size also increases the potential number of unemployed workers directly connected to any employed and informed worker. The information held by every employed worker is now shared by a larger group of unemployed workers, and unemployed workers exert an information sharing constraints on each other.

\footnotetext{
${ }^{7}$ Proofs of all propositions are in the Appendix.

${ }^{8}$ Alternatively, we can impose conditions on $v$ and $s$ such that $P(s, \cdot, v)$ is strictly convex in $u$ on the whole domain $[0,1]$. Indeed, whenever $v<4 /(7+3 s)$, we have $\widetilde{u}=0$, and $P$ as a function of $u$ is strictly convex with no restrictions (see the proof of Proposition 1 in the appendix).

${ }^{9}$ To be more precise, this is true only on a restricted domain $[0, K)$ including the unique global maximum $\bar{s}$.
} 
Another way to understand Proposition 1 is to highlight the coordination failures in the search process. Let $X$ be a random variable that represents the number of successes in the $s$ repeated independent Bernoulli trials reflecting word-of-mouth communication. $X$ gives the number of job vacancies passed on through word-of-mouth communication and follows the binomial distribution $B(\tau(s, u, v) ; s)$. Therefore, the expected number of job offers $E[X]$ that any unemployed worker hears about in a network of size $s$ is:

$$
E[X]=\tau(s, u, v)
$$

It is easy to see that $E[X]$ increases with $s$, is concave and converges to $v(1-u) / u$ as $s \rightarrow+\infty$. In other words, in larger networks, the unemployed workers hear about more jobs on average. However, as the network size $s$ increases, the support of the binomial distribution $B(\tau / s, s)$ also widens. This has a subtle countervailing effect. Indeed, the probability that an unemployed worker has at least one job offer is: ${ }^{10}$

$$
\operatorname{Pr}[X \geq 1]=1-\operatorname{Pr}[X=0]=1-\left[1-\frac{\tau(s, u, v)}{s}\right]^{s}
$$

It is straightforward to see that, holding $\tau / s$ constant, this probability (of hearing about multiple vacancies) increases when the support $s$ of the binomial distribution widens. This highlights the coordination failures of our model. When the network size $s$ increases, on average, the unemployed workers hear about more vacancies through their social network but, at the same time, it is more likely that multiple vacancies reach the same unemployed worker. We show in fact that there is a critical network size $\bar{s}$ above which the second effect dominates the first one. ${ }^{11}$ In sparse networks, more connections alleviate coordination failures by allowing a better partial replacement or job matches. In dense networks, though, more connections harm the matching process and slow down information exchange.

Results (ii) and (iii) in Proposition 1 are now quite easy to understand. When the unemployment rate $u$ increases, two effects are in order. First, the number of valuable information channels decreases. Second, the information sharing constraint exerted by unemployed workers on each other increases. As a result, $u$ and $P(s, \cdot, v)$ are negatively correlated. On the contrary, when $v$ increases, it is more likely that employed direct contacts possess redundant information, and more information is diffused through social interactions. As a result, $P(s, u, \cdot)$ increases with $v$.

\section{The matching function}

As stated above, unemployed workers find jobs using two different methods. Either they find their job directly with probability $v$, or they gather information about jobs through their social

\footnotetext{
${ }^{10}$ Of course, $\operatorname{Pr}[X \geq 1]=P(s, u, v)$.

${ }^{11}$ The threshold value $\bar{s}$ is uniquely determined by $\frac{\partial P(s, u, v)}{\partial s}=0$.
} 
contacts with probability $P(s, u, v)$. The job acquisition rate or individual hiring probability of an unemployed worker is:

$$
h(s, u, v)=v+(1-v) P(s, u, v)
$$

There are $u$ unemployed workers that find a job with probability $h(s, u, v)$. Since this probability is independent across different individuals, the rate at which job matches occur per unit of time is just $u h(s, u, v)$. Therefore, the matching function for our labor market where workers partly rely on personal contacts to find a job is given by: ${ }^{12}$

$$
m(s, u, v)=u[v+(1-v) P(s, u, v)]
$$

We can thus express the aggregate rate at which job matches occur as a function of the unemployed worker and vacant firm pools, and the social network underlying players talks. Contrary to previous contributions also providing a micro scenario for the matching function, the well-defined reduced function obtained here is neither an exponential nor a min one. Moreover, the central role of the network of contacts in matching job-seekers with vacancies is made explicit, and the link between $m(s, u, v)$ and the network size $s$ is precisely the key element of our model. ${ }^{13}$

Proposition 2 The properties of the matching function $m(s, u, v)$ are the following:

(i) $m(\cdot, u, v)$ increases on $[0, \bar{s}]$ and decreases on $[\bar{s}, n]$, where $\bar{s}$ is the unique global maximum of $P(\cdot, u, v)$. Also, $m(\cdot, u, v)$ is strictly concave on $[0, K)$ for some $K>\bar{s}$;

(ii) $m(s, \cdot, v)$ is increasing in $u$. Also, $m(s, \cdot, v)$ is strictly concave in $u$ on $[0, \bar{u}]$ for some $0<\bar{u} \leq$ 1 ;

(iii) $m(s, u, \cdot)$ is increasing and strictly concave in $v$.

The following comments are in order. First, there is a non-monotonic relationship between the job matching rate and the network size. In sparse networks, more contacts lead to a better information diffusion and increase the number of matches. In dense networks, more contacts slow down information diffusion and harm the matching process. Also, even though our matching function is quite different to the ones found in the literature, it has the same natural properties: it is increasing and strictly concave in both $u$ and $v .^{14}$

\footnotetext{
${ }^{12}$ To be more precise, the number of matches per unit of time is $n m(s, u, v)$.

${ }^{13}$ There are papers that have explored the wage premium associated with the use of personal contacts in finding a job. See for instance Montgomery (1991) for analysis of this issue in an adverse selection setting, Mortensen and Vishwanath (1994) for an equilibrium search models with wage posting and on-the-job search, and Montgomery (1992) for a model with weak and strong ties.

${ }^{14}$ For $u$, this is true only on a restricted domain $[0, \bar{u}]$, where $0<\bar{u} \leq 1$. Alternatively, one could impose restrictions on $v$ and $s$, instead. It is readily checked that $\bar{u}=1$ whenever $v<4 /(7+3 s)$.
} 
Second, it is easily verified that $P(s, u, v)$ is not homogeneous of degree one in $(u, v)$, implying in turn that the matching function $m(s, u, v)$ also fails to exhibit constant returns to scale (with respect to $u$ and $v$ ). The intuition for this result is as follows. Fix the network size $s$, and let $\lambda>1$. Increasing the vacancy rate from $v$ to $\lambda v$ has a positive direct impact on all workers in the population. By contrast, an increase in the unemployment rate from $u$ to $\lambda u$ has both a direct and an indirect negative effect. First, the number of unemployed direct acquaintances increases, thus reducing the value of such personal contacts as job providers (direct negative effect). Second, the number of unemployed indirect acquaintances also increases, and the information sharing constraint sharpens. More precisely, write (1) as ${ }^{15}$

$$
P(s, u, v)=1-\left[1-\frac{1}{s} v(1-u)\left(1+(1-u)+\cdots+(1-u)^{s-1}\right)\right]^{s}
$$

Increasing $v$ has a positive direct impact on $P$, whereas increasing $u$ has both a negative direct impact through $(1-u)$, and a negative magnifying impact through the polynomial form $1+(1-u)+$ $\cdots+(1-u)^{s-1}$. This result is at odds with the standard hypothesis in the job-matching theoretical literature of a constant-return-to-scale aggregate matching function (Mortensen and Pissarides, 1999 and Pissarides, 2000). If social networks and word-of-mouth communication are integrated in the job-search process, then the matching function is more likely not to be homogeneous of degree one. Besides, there is a huge body of empirical work to assess whether this property of the matching function is encountered in real-life labor markets. Even if the results lean towards constant returns to scale, they are very much controversial and most of these empirical studies do not include informal methods in finding a job. ${ }^{16}$

Finally, we can deduce from (3) the following simple expression for the individual probability $f(s, u, v)$ for firms to fill a vacancy:

$$
f(s, u, v)=\frac{m(s, u, v)}{v}=u\left[1-\left(1-\frac{1}{v}\right) P(s, u, v)\right]
$$

Clearly, the properties of both the job-hiring rate $h(s, u, v)$ and the job-filling rate $f(s, u, v)$ as functions of the network size $s$ are immediately deduced from that of $P(s, u, v)$ namely, strictly concave in $s$, increasing between 0 and $\bar{s}$ and decreasing between $\bar{s}$ and $n$. Moreover, the job-hiring rate $h(s, u, v)$ is decreasing in $u$ and increasing in $v$ whereas the job-filling rate $f(s, u, v)$ is increasing in $u$ and decreasing in $v \cdot{ }^{17}$ In other words, given a vacancy rate $v$ (and a network size $s$ ), when the number of unemployed increases, it is more difficult to find a job but easier to fill a vacancy.

\footnotetext{
${ }^{15}$ Simply note that$$
\left(1-(1-u)^{s}\right) /(1-(1-u))=1+(1-u)+\cdots+(1-u)^{s-1} .
$$

${ }^{16}$ See for instance Coles and Smith (1996), Petrongolo and Pissarides (2001) and the references therein.

${ }^{17}$ See Lemmata 1 and 2 in the appendix.
} 
Similarly, given an unemployment rate $u$ (and a network size $s$ ), it becomes easier to find a job but more difficult to fill a vacancy as the number of vacancies increases. ${ }^{18}$

\section{The labor market equilibrium}

\subsection{Free entry condition and labor demand}

We focus on the steady state equilibrium. Firms and workers are all identical. A firm is a unit of production that can either be filled by a worker whose production is either $y_{1}>0$ when the worker is long-term employed, and $y_{0}=0$ otherwise, or be unfilled and thus unproductive. Let $\gamma$ denote the search cost for the firm per unit of time, $w_{1}$ the wage paid by the firms to long-term employed workers, $w_{0}=0$ the wage paid during the probation period, and $r$ the discount factor.

At every period, matches between workers and firms depend upon the current network of social contacts of size $s$ and the current state of the economy summarized by $(u, v)$. We first establish the free-entry condition and the resulting labor demand.

Denote respectively by $I_{F, t}$ and $I_{V, t}$ the intertemporal profit of a filled job and of a vacancy at the beginning of period $t$, and before vacancies are posted. The job filling rate at the beginning of period $t$ is $f\left(s, u_{t-1}, v_{t}\right)$. We have the following Bellman equations: ${ }^{19}$

$$
\begin{gathered}
I_{F, t}=y_{1}-w_{1}+\frac{1}{1+r}\left[(1-\delta) I_{F, t+1}+\delta I_{V, t+1}\right] \\
I_{V, t}=-\gamma+\frac{1-f\left(s, u_{t-1}, v_{t}\right)}{1+r} I_{V, t+1}+f\left(s, u_{t-1}, v_{t}\right)\left[y_{0}-w_{0}+\frac{1}{1+r}\left((1-\delta) I_{F, t+1}+\delta I_{V, t+1}\right)\right]
\end{gathered}
$$

Indeed, a job already filled at the beginning of period $t$ and before vacancies are posted is held by a worker who has already completed his probation period and thus produces $y_{1}$, which implies (5). On the other hand, an unfilled vacancy at the beginning of period $t$ is immediately filled when posted with probability $f\left(s, u_{t-1}, v_{t}\right)$, in which cases it produces $y_{0}=0$ for the ongoing period, or remains unfilled with complementary probability $1-f\left(s, u_{t-1}, v_{t}\right)$, which implies (6). At steady state, $I_{F, t}=I_{F, t+1}=I_{F}, I_{V, t}=I_{V, t+1}=I_{V}, u_{t-1}=u$ and $v_{t}=v$. Following Pissarides (2000), we assume that firms post vacancies up to a point where $I_{V}=0$. Using (6), and the fact that $y_{0}=w_{0}=0$, we have:

$$
I_{F}=\frac{1+r}{1-\delta} \frac{\gamma}{f(s, u, v)}
$$

Using (5), this free entry implies:

$$
\frac{y_{1}-w_{1}}{r+\delta}=\frac{1}{1-\delta} \frac{\gamma}{f(s, u, v)}
$$

\footnotetext{
${ }^{18}$ See Pissarides (2000) for a thorough account and description of such trading externalities. Note also that $1 / h$ and $1 / f$ can be interpreted as the mean duration respectively of unemployment and of vacancies.

${ }^{19}$ Since $I_{V, t}$ is not standard, and even though $y_{0}=w_{0}=0$, we write $y_{0}$ and $w_{0}$ in the Bellman equation $I_{V, t}$ to better understand the timing of the model and the way $I_{V, t}$ is constructed.
} 
In other words, the value of a job is equal to the expected search cost, i.e. the net cost per unit of time multiplied by the average duration of search for the firm (i.e. $1 /[f(s, u, v)(1-\delta)])$. This equation can be mapped in the plane $(u, v)$ and is referred to as the labor demand curve. Observe that, even though this equation looks very much like the standard one (Pissarides, 2000), there is however a major difference. The size of the social network $s$ strongly affects the job-filling rate $f(s, u, v)$ and, as we will see below, the wage $w_{1}$. As a result, job creation and thus labor demand hinge on the network size.

\subsection{Wage determination}

Denote respectively by $I_{E, t}$ and $I_{U, t}$ the intertemporal gains of an employed and an unemployed worker at the beginning of period $t$ and before vacancies are posted. When vacancies are posted at the beginning of $t$, an unemployed worker finds a job with probability $h\left(s, u_{t-1}, v_{t}\right)$. We have the following standard Bellman equations for respectively the employed and unemployed workers: ${ }^{20,21}$

$$
\begin{gathered}
I_{E, t}=w_{1}+\frac{1}{1+r}\left[(1-\delta) I_{E, t+1}+\delta I_{U, t+1}\right] \\
I_{U, t}=\frac{1-h\left(s, u_{t-1}, v_{t}\right)}{1+r} I_{U, t+1}+h\left(s, u_{t-1}, v_{t}\right)\left[w_{0}+\frac{1}{1+r}\left((1-\delta) I_{E, t+1}+\delta I_{U, t+1}\right)\right]
\end{gathered}
$$

The interpretation of those equations follows, mutatis mutandis, from the equations for the firm. At steady state, $I_{E, t}=I_{E, t+1}=I_{E}, I_{U, t}=I_{U, t+1}=I_{U}, u_{t-1}=u$ and $v_{t}=v$, and the worker surplus obtained from (9) and (10) is (using the fact that $w_{0}=0$ ):

$$
I_{E}-I_{U}=\frac{(1+r)}{r+\delta+(1-\delta) h(s, u, v)} w_{1}
$$

We now determine the earnings of $w_{1}$ the long-term employed workers. This wage $w_{1}$ is derived from a generalized Nash-bargaining process over the total intertemporal surplus between the firm and the worker. ${ }^{22}$ Given that the firm surplus is equal to $I_{F}-I_{U}$, the wage of a worker who has completed his probation period is given by:

$$
w_{1}=\operatorname{Arg} \max \left(I_{E}-I_{U}\right)^{\beta}\left(I_{F}-I_{V}\right)^{1-\beta}
$$

where $0 \leq \beta \leq 1$ denotes the bargaining power of workers. Observe that $I_{U}$ is the value of continued search, i.e. the value of workers' outside option whereas $I_{V}$ equals the employers' value of holding the job vacant, i.e. the value of firms' outside option. The first-order maximization condition is:

$$
(1-\beta)\left(I_{E}-I_{U}\right)=\beta\left(I_{F}-I_{V}\right)
$$

\footnotetext{
${ }^{20}$ Observe that, at the beginning of period $t$, a worker has at least worked one period and thus earn a wage $w_{1}$ while producing $y_{1}$.

${ }^{21}$ Once again, in order to better understand $I_{U, t}$ and the timing of the model, we have put $w_{0}$ in the Bellman equation $I_{U, t}$, even though it is equal to zero.

${ }^{22}$ All negotiations take place between two agents: the worker and the firm. In particular, no agent is allowed to make offers simultaneously to more than one other agent.
} 
Now, observing that $I_{V}=0$ (free-entry condition), and using (7), (8) and (11), and the fact that $h(s, u, v) / f(s, u, v)=v / u$, we have:

$$
w_{1}=\beta\left(y_{1}+\gamma \frac{v}{u}\right)
$$

We obtain here exactly the same wage as in a standard matching model without social networks (see equation (1.20), page 17, in Pissarides, 2000) in which the unemployment benefit is normalized to zero. There is however two main differences. First, here we do not have constant returns to scale in the matching function so that we cannot express the wage directly in terms of labor market tightness but rather in the ratio $v / u$. Second, and this is much more crucial, in equilibrium $u$ and $v$ depend on the size of the social network, which implies that the wage $w_{1}$ itself depends on $s$. The relationship between $w_{1}$ and $s$ is non-trivial and will be investigated in equilibrium in section 4.4. Of course, apart of $s$, the comparative statics on $w_{1}$ are similar to the standard ones: an increase in $y_{1}, \beta$ or $\gamma$ increases the wage since it rises the bargaining power of workers.

\subsection{Steady-state labor market equilibrium}

At the beginning of each period, some workers find a job, and the employment pool consists of those workers already employed by then (long-term employed) and these newly-employed ones. At the end of each period, each job is destroyed according to some exogenous Poisson process at a rate $\delta$. Therefore, only a fraction $(1-\delta)$ of currently employed workers keep their job. Between the end of period $t-1$ and the end of period $t$, the rate of workers who first leave unemployment is given by $u_{t-1} h\left(s, u_{t-1}, v_{t}\right)$, whereas the rate of workers who then enter unemployment is $\delta\left[1-u_{t-1}+u_{t-1} h\left(s, u_{t-1}, v_{t}\right)\right]$. The evolution of the unemployment rate is given by the difference between these two flows:

$$
u_{t}-u_{t-1}=\delta\left(1-u_{t-1}\right)-(1-\delta) u_{t-1} h\left(s, u_{t-1}, v_{t}\right) .
$$

In steady state, the unemployment rate as well as the vacancy rate are constant, i.e. $u_{t-1}=$ $u_{t}=u$ and $v_{t-1}=v_{t}=v$, and flows out of unemployment equate flows into unemployment. We thus have:

$$
(1-\delta) m(s, u, v)=\delta(1-u) .
$$

As above, this equation can be mapped in the plane $(u, v)$ and is referred to as the Beveridge curve.

Fix the network size $s$ and consider the associated matching technology $m(s, \cdot, v)$ given by (3). A steady-state equilibrium consists on an unemployment rate $u^{*}(s)$, a vacancy rate $v^{*}(s)$ and a wage level for long-term employed $w_{1}^{*}(s)$ at the intersection of the Beveridge curve and the labor demand curve, and satisfying the wage-setting equation (12). A steady state equilibrium $\left(u^{*}(s), v^{*}(s), w_{1}^{*}(s)\right)$ is thus a solution to the system of equations (8), (12) and (14). Plugging (12) into $(8),\left(u^{*}(s), v^{*}(s)\right)$ is given by the following system of two equations: 


$$
\begin{gathered}
(1-\delta) m\left(s, u^{*}(s), v^{*}(s)\right)=\delta\left(1-u^{*}(s)\right) \\
y_{1}=\frac{\gamma}{1-\beta}\left[\frac{r+\delta}{(1-\delta) f\left(s, u^{*}(s), v^{*}(s)\right)}+\beta \frac{v^{*}(s)}{u^{*}(s)}\right]
\end{gathered}
$$

and the wage is then given by:

$$
w_{1}^{*}(s)=\beta\left(y_{1}+\gamma \frac{v^{*}(s)}{u^{*}(s)}\right)
$$

Proposition 3 Suppose that $1 \geq \gamma[r+\delta+(1-\delta) \beta] / y_{1}(1-\beta)(1-\delta)>\delta$. Then, for all network size $s$, there exists a unique labor market equilibrium $\left(u^{*}(s), v^{*}(s), w^{*}(s)\right)$.

\subsection{Social network, wages and unemployment}

We now investigate the different properties of the labor market equilibrium. We relate the equilibrium unemployment rate $u^{*}(s)$ to the network size $s$. We assume from now on that the conditions for uniqueness are met.

Proposition 4 The equilibrium unemployment rate $u^{*}(s)$ decreases with $s$ when $s<\bar{s}$, while it increases when $s \geq \bar{s}$.

Our matching function depends explicitly on the structure of personal contacts and the labor market equilibrium captures the influence of the frictions due to workers social embeddedness on market outcomes. In particular, we know from propositions 1 and 2 that in a sparse network $(s<\bar{s})$, both the individual probability $P(\cdot, u, v)$ to find a job through word-of-mouth and the matching function increase with the network size $s$. We deduce from the free entry condition (8) that, holding the arrival rate $v$ fixed, unemployment decreases. The Beveridge curve (15) then implies that unemployment must also decrease to equalize flows out with flows in. Since the two effects have the same sign, $u^{*}(s)$ decreases with $s$. When the social network of contacts is dense $(s \geq \bar{s})$, the opposite result holds since negative network externalities prevail in networks of large size and both $P(\cdot, u, v)$ and $m(\cdot, u, v)$ decrease with $s$.

The impact of the network size $s$ on the equilibrium vacancy rate $v^{*}(s)$ is ambiguous both when the network is sparse $(\bar{s}>s)$ or dense $(s \geq \bar{s})$. Indeed, two opposite effects are now in place. On one hand, increasing the size of a sparse network improves the transmission of information through word-of-mouth communication. As a result, matches are more frequent and the free-entry condition (8) implies that more vacancies are posted. In other words, $v^{*}(s)$ and $s$ are positively correlated. On the other hand, when the number of matches between workers and firms increase, the Beveridge curve (15) adjusts the vacancy rate downwards so as to equate the flows out of unemployment with the flows into unemployment. Therefore, $v^{*}(s)$ and $s$ are negatively correlated. When the network is dense, this ambiguity remains and is sustained by the opposite intuition: $v^{*}(s)$ and $s$ are both negatively and positively correlated due to (8) and (15) respectively. 
Finally, given that the long-term equilibrium wage is determined by (17), we easily obtain

$$
\frac{d w_{1}^{*}(s)}{d s}=\beta \gamma \frac{d}{d s}\left(\frac{v^{*}(s)}{u^{*}(s)}\right)=\frac{\beta \gamma}{u^{*}(s)^{2}}\left[\frac{d v^{*}}{d s} u^{*}-\frac{d u^{*}}{d s} v^{*}\right]
$$

The comparative statics of $w_{1}^{*}$ with respect to the network size $s$ follow that of the labor market tightness $v^{*} / u^{*}$. If the network size has a negative impact on the market tightness, wages decrease with network size. If, on the contrary, the network size positively affects the market tightness, then wages increase with $s$. Unfortunately, the ambiguity of the relationship between $s$ and $v^{*}(s)$ translates to the equilibrium wage level, and we can not conclude on the precise direction of these effects. To see this, observe that

$$
\frac{d w_{1}^{*}(s)}{d s} \gtrless 0 \Leftrightarrow \eta_{v s} \gtrless \eta_{u s}
$$

where $\eta_{v s}=\left(d v^{*} / d s\right)(s / v)$ and $\eta_{u s}=\left(d u^{*} / d s\right)(s / u)$ are respectively the elasticity of the vacancy rate with respect to $s$ and the elasticity of the unemployment rate with respect to $s$.

\section{Welfare analysis}

In the standard search-matching literature, market failures are caused by search externalities. Two types of externalities must be considered: $(i)$ negative intra-group externalities (more searching workers reduces the job-hiring rate, and more searching firms reduce the job-filling rate) and (ii) positive inter-group externalities (more searching workers increases the job-filling rate, and more searching firms increase the job-hiring rate). For a class of related search-matching models, Hosios (1990) and Pissarides (2000) have established that these two externalities just offset one another in the sense that search equilibrium is socially efficient if and only if the matching function is homogenous of degree one and the worker's share of surplus $\beta$ is equal to $\eta$ the elasticity of the matching function with respect to unemployment (this is referred to as the Hosios-Pissarides condition). ${ }^{23}$ Of course, there is no reason for $\beta$ to be equal to $\eta$ since these two variables are not related at all and, therefore, the search-matching equilibrium is in general inefficient. When $\beta$ is larger than $\eta$, there is too much unemployment, creating congestion in the matching process for the unemployed. When $\beta$ is lower, there is too little unemployment, creating congestion for firms.

In the present model, we have exactly the same externalities (intra- and inter-group externalities). But the network of social contacts adds an additional externality since the matching technology depends on the number of social contacts (see our discussion in section 2.3). Our steady-state

\footnotetext{
${ }^{23}$ Formally,

$$
\eta=-\frac{\partial f(\theta)}{\partial \theta} \frac{\theta}{f(\theta)}
$$

where $\theta=v / u$ is the labor market tightness, and $f(\theta)$ is the probability to fill a vacancy.
} 
equilibrium is thus expected not to be efficient, unless some stringent conditions are satisfied. Contrarily to previous models, this conditions are parameterized by an external parameter, the network size $s$.

The welfare function is given by ${ }^{24,25}$

$$
\mathcal{W}=\sum_{t=1}^{+\infty} \frac{1}{(1+r)^{t}}\left[b u_{t-1}\left[1-h\left(s, u_{t-1}, v_{t}\right)\right]+y_{1}\left(1-u_{t-1}\right)+y_{0} u_{t-1} h\left(s, u_{t-1}, v_{t}\right)-\gamma v_{t}\right]
$$

Observe that wages do not appear in the welfare function since there are pure transfers. The social planner chooses $u_{t}$ and $v_{t}$ that maximize (18) under the constraint (13). Let

$$
\eta_{m v}=\frac{\partial m}{\partial v} \frac{v}{m}>0
$$

denote the elasticity of the matching function with respect to the vacancy rate. We have the following results.

Proposition 5 In steady state, the private and the social outcomes coincide if and only if

$$
\beta=\frac{1+r-(r+\delta) \eta_{m v}(s, u, v)}{1+r+(1-\delta) \eta_{m v}(s, u, v) h(s, u, v)}
$$

It is readily checked that $\beta<1$. Furthermore, $\beta>0$ if and only if $\eta_{m v}(s, u, v)<(1+r) /(r+\delta)$. When this condition is met, there exists a value of $\beta$ (the bargaining power of workers) for which the decentralized market equilibrium is efficient. This value depends on the network size $s$ through the elasticity $\eta_{m v}(s, u, v)$ and the hiring rate $h(s, u, v)$. Two markets with different underlying structures of social contacts could thus be efficient for different values of the workers' bargaining power. In other words, the efficiency properties of labor market institutions, such as the wagesetting procedure, depend upon the social environment within which the market is embedded, and different social environments call for different institutional arrangements.

More generally, the result obtained confirms our initial intuition. Unless a drastic condition (19) is met, the decentralized market equilibrium is not efficient because of the presence of both search and network externalities.

\footnotetext{
${ }^{24}$ Indeed, among the $n u_{t-1}$ workers unemployed at the end of period $t-1$, a fraction $h\left(s, u_{t-1}, v_{t}\right)$ finds a job at the beginning of period $t$, and produces $y_{0}$ during the ongoing probatory period, whereas a (complementary) fraction $1-h\left(s, u_{t-1}, v_{t}\right)$ remains unemployed all along this period. The remaining $n\left(1-u_{t-1}\right)$ workers are longterm employed during all period $t$ (that is, they have been holding the same position for at least two consecutive periods), and produce $y_{1}$.

${ }^{25}$ Here also, to better understand the way the welfare function is constructed, $y_{0}, w_{0}$ and $b$ are introduced in (18), even though they are all equal to zero by assumption.
} 


\section{Conclusion}

In recent years, a growing literature consisting both of empirical work and theoretical contributions has stressed the prominence of social networks in explaining a wide range of economic phenomena. In particular, the prevalent social contacts strongly determine, or at least influence, economic success of individuals in a labor market context.

In this paper, we have analyzed the job matching between unemployed workers and vacant jobs in a social network context. More precisely, each individual, who is embedded within a network of social relationships, can find a job either directly or indirectly through informal networks (word-ofmouth communication). From this micro scenario, we first derive an aggregate matching function that has the standard properties but fails to be homogenous of degree one. This is because there is a non-monotonic relationship between the size of the social network and the probability to find a job: increasing the size of sparse networks is beneficial to workers whereas it is detrimental in dense networks because of negative network externalities. We then close the model by introducing the behavior of firms and the wage determination and show that there exists a unique labor market equilibrium under mild conditions on the parameters of the economy. Because of the previous

result, we show that the equilibrium unemployment rate decreases with the network size in sparse networks while it increases in dense networks. Finally, we show that the equilibrium is not in general efficient and derive a condition similar to the Hosios-Pissarides one.

\section{References}

[1] Bala, V. and S. Goyal (1998), "Learning from neighbours", Review of Economic Studies 65, 595-621.

[2] Bala, V. and S. Goyal (2000), "A non-cooperative theory of network formation", Econometrica $68,1181-1230$.

[3] Blanchard, O.J. and P. Diamond (1994), "Ranking, unemployment duration, and wages", Review of Economic Studies 61, 417-434.

[4] Boorman, S.A. (1975), "A combinatorial optimization model for transmission of job information through contact networks", Bell Journal of Economics 6, 216-249.

[5] Burdett, K., Shi, S. and R. Wright (2001), "Pricing with frictions", Journal of Political Economy 109, 1060-1085.

[6] Butters, G. (1977), "Equilibrium distributions of sales and advertising prices", Review of Economic Studies 44, 465-491. 
[7] Calvó-Armengol, A. (2001), "Job contact networks", mimeo, www.eco.uc3m.es/ ancalvo/jobnet.pdf

[8] Coles, M.G. and E. Smith (1996), "Cross-section estimation of the matching function: evidence from England and Wales", Economica 63, 589-597.

[9] Corcoran, M., Datcher, L. and G.J. Duncan (1980), "Most workers find jobs through word of mouth", Monthly Labor Review 103, 33-35

[10] Diamond, P. (1981), "Mobility costs, frictional unemployment, and efficiency", Journal of Political Economy 89, 798-812.

[11] Ellison, G. and D. Fudenberg (1995), "Word-of-mouth communication and social learning", Quarterly Journal of Economics 110, 93-126.

[12] Granovetter, M.S. (1995), Getting a Job: A Study of Contacts and Careers, Cambridge, MA: Harvard University Press.

[13] Hall, R.E. (1979), "A theory of the natural unemployment rate and the duration of employment", Journal of Monetary Economics 5, 153-169.

[14] Holzer, H. (1988), "Search method used by unemployed youth", Journal of Labor Economics $6,1-20$.

[15] Hosios, A. (1990), "On the efficiency of matching and related models of search and unemployment", Review of Economic Studies 57, 279-298.

[16] Jackson, M.O. and A. Wolinsky (1996), "A strategic model of social and economic networks", Journal of Economic Theory 71, 44-74.

[17] Lagos, R. (2000), "An alternative approach to search frictions", Journal of Political Economy 108, 851-873.

[18] Montgomery, J.D. (1991), "Social networks and labor-market outcomes: toward and economic analysis", American Economic Review 81, 1408-1418.

[19] Montgomery, J.D. (1992), "Job search and network composition: Implications of the strengthof-weak-ties hypothesis", American Sociological Review 57, 586-596.

[20] Mortensen, D.T. and C.A. Pissarides (1999), "New developments in models of search in the labor market", in Card, D. and O. Ashenfelter (eds.), Handbook of Labor Economics, Amsterdam: Elsevier Science, ch.39, 2567-2627.

[21] Mortensen, D.T. and T. Vishwanath (1994), "Personal contacts and earnings: it is who you know!", Labour Economics 1, 187-201. 
[22] Peters, M. (1991), "Ex ante price offers in matching games non-steady states", Econometrica 59, 1425-1454.

[23] Petrongolo, B. and C.A. Pissarides (2001), "Looking into the black box: a survey of the matching function", Journal of Econmic Literature 39, 390-431.

[24] Pissarides, C.A. (1979), "Job matchings with state employment agencies and random search", Economic Journal 89, 818-833.

[25] Pissarides, C.A. (2000), Equilibrium Unemployment Theory, 2nd edition, Cambridge: MIT Press.

[26] Smith, T.E. and Y. Zenou (2003), "A discrete-time stochastic model of job matching", Review of Economic Dynamics 6, 54-79.

[27] Topa, G. (2001), "Social interactions, local spillovers and unemployment", Review of Economic Studies 68, 261-295. 


\section{A Appendix}

\section{Proof of Proposition 1.}

Let $q(s, u)=(1-u)\left[1-(1-u)^{s}\right] / s u$. Let $Q(s, u, v)=[1-v q(s, u)]^{s}$. Then, $P(s, u, v)=$ $1-Q(s, u, v)$, and we deduce the properties of $P$ from those of $Q$ established below.

(a) $Q(s, u, \cdot)$ is decreasing and strictly convex with respect to $v$. Indeed, differentiating once with respect to $v$ gives: $\partial Q / \partial v=-s Q /(1-v q)<0$. Differentiating twice: $\partial^{2} Q / \partial v^{2}=$ $-s q(\partial Q / \partial v) /(1-v q)-s q^{2} Q /(1-v q)^{2}$. Replacing $\partial Q / \partial v$ by its expression above gives $\partial^{2} Q / \partial v^{2}=s(s-1) q^{2} Q /(1-v q)^{2}>0$.

(b) $Q(s, \cdot, v)$ is increasing and strictly concave with respect to $u$. Indeed, simplifying by $1-$ $(1-u)$, we get $q(s, u)=\left[(1-u)+\cdots+(1-u)^{s}\right] / s$. Thus $q$ increases in $u$, implying that $Q$ decreases in $u$. The function $q$ is a polynomial in $u$ of degree $s$, and $Q$ is thus a polynomial in $u$ of degree $2 s$. Fix $v$ and $s$. Given that $Q$ is an increasing function of $u, \partial Q / \partial u>0$ on $(0,1)$, meaning that the polynomial $\partial Q / \partial u$ in $u$ of degree $2 s-1$ has no roots on $(0,1)$. Successive derivatives of polynomials have nested roots. Therefore, the polynomial $\partial^{2} Q / \partial u^{2}$ in $u$ of degree $2 s-2$ has at most one root on $(0,1)$ and changes sign at most once on that interval. Differentiating twice gives

$$
\frac{\partial^{2} Q}{\partial u^{2}}=-v s(1-v q)^{s-2}\left[(1-v q) \frac{\partial^{2} q}{\partial u^{2}}-v(s-1)\left(\frac{\partial q}{\partial u}\right)^{2}\right],
$$

where

$$
\left\{\begin{array}{l}
\frac{\partial q}{\partial u}=-\frac{1}{s}\left[1+\cdots+s(1-u)^{s-1}\right] \\
\frac{\partial^{2} q}{\partial u^{2}}=\frac{1}{s}\left[2+\cdots+s(s-1)(1-u)^{s-2}\right]
\end{array} .\right.
$$

We have

$$
\left\{\begin{array}{l}
q(s, 1)=0 \\
\frac{\partial q(s, 1)}{\partial u}=-\frac{1}{s} \\
\frac{\partial^{2} q(s, 1)}{\partial u^{2}}=\frac{2}{s}
\end{array} .\right.
$$

Therefore, $\partial^{2} Q(s, 1, v) / \partial u^{2}=-v[2-v(s-1) / s]<0$. Given that $\partial^{2} Q(s, \cdot, v) / \partial u^{2}$ is continuous and changes sign at most once in $[0,1]$,there exists $0 \leq \widetilde{u}<1$ such that $\partial^{2} Q / \partial u^{2}<0$ on $[\widetilde{u}, 1]$. Also,

$$
\left\{\begin{array}{l}
q(s, 0)=1 \\
\frac{\partial q(s, 0)}{\partial u}=-\frac{s+1}{2} \\
\frac{\partial^{2} q(s, 0)}{\partial u^{2}}=\frac{s\left(s^{2}-1\right)}{3}
\end{array} .\right.
$$

Therefore, $\partial^{2} Q(s, 0, v) / \partial u^{2}=-12 s\left(s^{2}-1\right) v(1-v)^{s-2}[4-v(7 s+3)]$. Hence, $\partial^{2} Q(s, 0, v) / \partial u^{2}<$ 0 if and only if $4-v(7 s+3)>0$. Given that $\partial^{2} Q(s, \cdot, v) / \partial u^{2}$ is continuous and changes sign 
at most once on $[0,1]$, whenever $4-v(7 s+3)>0$, we have $\widetilde{u}=0$, and $\partial^{2} Q(s, u, v) / \partial u^{2}<0$, for all $u \in[0,1]$.

(c) $Q(\cdot, u, v)$ is decreasing in $[0, \bar{s}]$ and increasing on $[\bar{s}, n]$. Moreover, is strictly convex on $[0, K)$ for some $K>\bar{s}$. We prove this result in four steps. Fix $u$ and $v$ and let $\phi(s)=1-v q(s, u)$. Then, $Q=\phi(s)^{s}$ implying that $\partial Q / \partial s=\Phi Q$, where $\Phi(s)=\ln \phi(s)+s \phi^{\prime}(s) / \phi(s)$.

Step 1. We show that $\partial Q(1, u, v) / \partial s<0$, equivalent to $\Phi(1)<0$. With some algebra,

$$
\phi^{\prime}(s)=v \frac{(1-u)}{u}\left[\frac{1-(1-u)^{s}}{s^{2}}+\frac{(1-u)^{s}}{s} \ln (1-u)\right]
$$

implying that

$$
\frac{\Phi(1)}{1-v(1-u)}=v(1-u)\left[1+\frac{1-u}{u} \ln (1-u)\right]+[1-v(1-u)] \ln [1-v(1-u)] .
$$

$\Phi(1)<0$ is thus equivalent to $\rho_{u}(v)<0$ on $(0,1)$, for all $u \in[0,1]$, where

$$
\rho_{u}(v)=v(1-u)\left[1+\frac{1-u}{u} \ln (1-u)\right]+[1-v(1-u)] .
$$

Fix $u$. Differentiating twice gives

$$
\rho_{u}^{\prime}(v)=\frac{(1-u)^{2}}{u} \ln (1-u)-(1-u) \ln [1-v(1-u)]
$$

and $\rho_{u}^{\prime \prime}(v)=(1-u)^{2} /[1-v(1-u)]>0$. Therefore, $\rho_{u}$ is strictly convex, implying that $\rho_{u}^{\prime}$ increases on $(0,1)$ with supremum

$$
\rho_{u}^{\prime}(1)=\frac{1-u}{u}[(1-u) \ln (1-u)-u \ln u] .
$$

The function $x \mapsto(1-x) \ln (1-x)-x \ln x$ is worth 0 at $x=0,1 / 2$ and 1 , takes positive values on $(0,1 / 2)$ and negative values on $(1 / 2,1)$. Therefore, if $u \in(1 / 2,1)$, $\rho_{u}^{\prime}(1)<0$, implying that $\rho_{u}^{\prime}(v)<0$ on $(0,1)$, and $\Phi(1)<0$. Suppose now that $u \in(0,1 / 2)$. Then, $\rho_{u}^{\prime}(1)>0$. It is easy to see that $\rho_{u}^{\prime}(0)<0$. Given, that $\rho$ is convex, $\rho$ first decreases and then increases with supremum given by $\max \left\{\rho_{u}(0), \rho_{u}(1)\right\}$. We have $\rho_{u}(0)=0$ and $\rho_{u}(1)=(1-u)(1+(1-u) \ln (1-u) / u)+u \ln u$. If $u<1 / 2$, $(1-u) \ln (1-u)>u \ln u$, and $\rho_{u}(1)<(1-u)[u+\ln (1-u)] / u$. It is easy to check that $x \mapsto 1-x+\ln x$ is negative on $(0,1)$. Hence, $\rho_{u}(1)<0$, and $\Phi(1)<0$. Q.E.D.

Step 2. We show that $Q(\cdot, u, v)$ increases towards its asymptotic limit for high values of $s$. In fact, $\Phi(s) \sim[v(1-u) / s u]^{2}$ when $s \rightarrow+\infty$, implying that $\partial Q / \partial s>0$ for high values of $s$. Therefore, $Q(\cdot, u, v)$ increases towards its limit $\exp (-v(1-u) / u)$ when $s \rightarrow+\infty$.

Q.E.D. 
Step 3. We show that $\partial Q / \partial s \leq 0$ implies that $\partial^{2} Q / \partial s^{2}>0$. We have $\partial Q / \partial s=\Phi Q$. Hence, $\partial^{2} Q / \partial s^{2}=\Phi^{\prime} Q+\Phi \partial Q / \partial s=\left(\Phi^{\prime}+\Phi^{2}\right) Q$. Therefore, $\Phi^{\prime}>0$ implies $\partial^{2} Q / \partial s^{2}>$ 0 . Suppose now that $\Phi^{\prime} \leq 0$. We have $\phi(s)=1-v(1-u)\left[1-(1-u)^{s}\right] / s u \rightarrow 1$ and $s \phi^{\prime}(s)=v(1-u)\left\{\left[1-(1-u)^{s}\right] / s+(1-u)^{s} \ln (1-u)\right\} / u \rightarrow 0$ when $s \rightarrow+\infty$. Therefore, $\lim _{s \rightarrow+\infty} \Phi(s)=0$. Hence, $\Phi^{\prime} \leq 0$ implies that $\Phi>0$. Reciprocally, $\Phi \leq 0$ implies that $\Phi^{\prime}>0$, which in turn implies that $\partial^{2} Q / \partial s^{2}>0$. But $\Phi \leq 0$ is equivalent to $\partial Q / \partial s \leq 0$. Hence, $\partial Q / \partial s \leq 0$ implies that $\partial^{2} Q / \partial s^{2}>0$.

Q.E.D.

Step 4. We deduce from steps 1 and 2 that $\partial Q / \partial s=0$ for some $\bar{s} \in[1, n]$. From step $3, \partial^{2} Q(\bar{s}, u, v) / \partial s^{2}>0$. Therefore, there exists a unique such point $\bar{s}$, and $Q(\cdot, u, v)$ reaches its global minimum at $\bar{s}$. Moreover, by continuity of $\partial^{2} Q / \partial s^{2}$, there exists some $K>\bar{s}$ such that $Q(\cdot, u, v)$ is strictly convex on $[1, K)$.

Q.E.D.

\section{Proof of Proposition 2.}

Recall that $m(s, u, v)=u[v+(1-v) P(s, u, v)]$. Therefore,

(a) the properties of the matching function $m(\cdot, u, v)$ with respect to $s$ are deduced from that of $P(\cdot, u, v)$ given in Proposition $1(i i)$.

(b) With some algebra and using Proposition 1 we get:

$\left\{\begin{array}{l}\frac{\partial m(s, u, v)}{\partial v}=u[1-P(s, u, v)]+u(1-v) \frac{\partial P(s, u, v)}{\partial v}>0 \\ \frac{\partial^{2} m(s, u, v)}{\partial v^{2}}=-2 u \frac{\partial P(s, u, v)}{\partial v}+u(1-v) \frac{\partial^{2} P(s, u, v)}{\partial v^{2}}<0\end{array}\right.$

proving that $m(s, u, \cdot)$ is increasing and concave with respect to $v$.

(c) With some algebra we get:

$\left\{\begin{array}{l}\frac{\partial m(s, u, v)}{\partial u}=v+(1-v) \frac{\partial}{\partial u}[u P(s, u, v)] \\ \frac{\partial^{2} m(s, u, v)}{\partial u^{2}}=(1-v) \frac{\partial^{2}}{\partial u^{2}}[u P(s, u, v)]\end{array}\right.$

Simplifying by $u$, we deduce from (1) that

$$
P(s, u, v)=1-\left[1-\frac{v}{s}\left((1-u)+(1-u)^{2}+\cdots+(1-u)^{s}\right)\right]^{s} .
$$

Fix $v$ and $s$ and let $R(u)=u P(s, u, v)$. Clearly, $R(u)$ is a polynomial in $u$ of degree $2 s+1$, with roots 0 and 1 (that is, $R(0)=R(1)=0$ ) and strictly positive on $(0,1)$. Given that successive derivatives of polynomials have nested roots, we deduce that $R^{\prime}(u)=$ $u \partial P(s, u, v) / \partial u+P(s, u, v)$ is a polynomial of degree $2 s$ with a unique root $\widetilde{u} \in(0,1)$ corresponding to the global maximum of $R$ on $[0,1]$. From $R^{\prime}(u)$ continuous and $R^{\prime}(0)=$ $P(s, 0, v)>0$ we deduce that $R^{\prime}(u)>0$ on $(0, \widetilde{u})$ and that $R^{\prime \prime}(u)$ is negative locally around 
$\widetilde{u}$ that is, $R^{\prime \prime}(u)<0$ on $(\widetilde{u}-\varepsilon, \widetilde{u}+\varepsilon)$ for some $\varepsilon>0$. We also deduce from $R^{\prime \prime}(u)=$ $u \partial^{2} P / \partial u^{2}+2 \partial P / \partial u$ and Proposition $1(i i)$ that $R^{\prime \prime}(0)=2 \partial P(s, 0, v) / \partial u<0$. If $R^{\prime \prime}(u)$ were to change sign on $[0, \widetilde{u}]$, by continuity of $R^{\prime \prime}$ and because both $R^{\prime \prime}(0)<0$ and $R^{\prime \prime}(\bar{u})<0$, it would imply that $R^{\prime \prime}(u)$ had two distinct roots on $(0, \widetilde{u})$, which is impossible because successive derivatives of polynomials have nested roots, and $R^{\prime}(u)$ has only one root on $[0,1]$. Therefore, $R^{\prime \prime}(u)<0$ on $[0, \widetilde{u}]$. Let $\bar{u}=\arg \max \left\{u \in[0,1] \mid R^{\prime}>0\right.$ and $R^{\prime \prime}<0$ on $\left.[0, u]\right\}$. Clearly, $0<\widetilde{u} \leq \bar{u} \leq 1$.

Lemma 1 The hiring probability $h(s, u, v)=m(s, u, v) / u$ is decreasing in $u$ and increasing in $v$. The properties of $h(\cdot, u, v)$ with respect to $s$ are the same than that of $P(\cdot, u, v)$.

Proof. Recall that $h(s, u, v)=v+(1-v) P(s, u, v)$. With some algebra and using Proposition 1 we get:

$$
\left\{\begin{array}{l}
\frac{\partial h(s, u, v)}{\partial u}=(1-v) \frac{\partial P(s, u, v)}{\partial u}<0 \\
\frac{\partial h(s, u, v)}{\partial v}=1-P(s, u, v)+(1-v) \frac{\partial P(s, u, v)}{\partial v}>0
\end{array}\right.
$$

which completes the proof.

Lemma 2 The filling probability $f(s, u, v)=m(s, u, v) / v$ is increasing in $u$ and decreasing in $v$. The properties of $f(\cdot, u, v)$ with respect to $s$ are the same than that of $P(\cdot, u, v)$.

Proof. Recall that $f(s, u, v)=u\left[1-\left(1-\frac{1}{v}\right) P(s, u, v)\right]$. With some algebra and using Proposition 1 we get:

$$
\left\{\begin{array}{l}
\frac{\partial f(s, u, v)}{\partial u}=\frac{f(s, u, v)}{u}-u\left(1-\frac{1}{v}\right) \frac{\partial P(s, u, v)}{\partial u}>0 \\
\frac{\partial f(s, u, v)}{\partial v}=-\frac{u}{v^{2}} P(s, u, v)-u\left(1-\frac{1}{v}\right) \frac{\partial P(s, u, v)}{\partial v}<0
\end{array}\right.
$$

which completes the proof.

\section{Proof of Proposition 3.}

Fix the network size $s$. The labor market equilibrium is characterized by (15) and (16). We first prove that along the Beveridge curve, $u$ is decreasing in $v$. Indeed, let $(u, v)$ and $\left(u^{\prime}, v^{\prime}\right)$ both satisfying (15) with $v^{\prime}>v$. By definition, $(1-\delta) m(s, u, v)=\delta(1-u)$ and $(1-\delta) m\left(s, u^{\prime}, v^{\prime}\right)=$ $\delta\left(1-u^{\prime}\right)$. Suppose that $u^{\prime} \geq u$. Then, $m\left(s, u^{\prime}, v^{\prime}\right) \leq m(s, u, v)$. But we deduce from Proposition 2 that $m(s, u, v)<m\left(s, u, v^{\prime}\right) \leq m\left(s, u^{\prime}, v^{\prime}\right)$ which yields to a contradiction. Therefore, $u^{\prime}<u$.

We now prove that along the curve (16), $u$ is increasing in $v$. Indeed, the implicit function theorem and Lemma 2 imply

$$
\frac{d v}{d u}=\frac{\frac{r+\delta}{(1-\delta) f(s, u, v)^{2}} \frac{\partial f(s, u, v)}{\partial u}+\beta \frac{v}{u^{2}}}{-\frac{r+\delta}{(1-\delta) f(s, u, v)^{2}} \frac{\partial f(s, u, v)}{\partial v}+\frac{\beta}{u}}>0
$$


If a labor market equilibrium exists, it is thus unique. We now prove existence. At $v=1$, $m(s, u, 1)=u$. We deduce from $(15)$ that $(\delta, 1)$ belongs to the Beveridge curve. Also, $\left(\frac{\gamma}{y_{1}} \frac{r+\delta+(1-\delta) \beta}{(1-\beta)(1-\delta)}, 1\right)$ satisfies (16) (which requires that $\frac{\gamma}{y_{1}} \frac{r+\delta+(1-\delta) \beta}{(1-\beta)(1-\delta)} \leq 1$ ). A necessary and sufficient condition for an equilibrium to exist is thus $\frac{\gamma}{y_{1}} \frac{r+\delta+(1-\delta) \beta}{(1-\beta)(1-\delta)}>\delta$.

\section{Proof of Proposition 4.}

Let $(u, v)$ on the Beveridge curve, thus satisfying (15). Let $\bar{s} \geq s^{\prime}>s$. We know from Proposition 2 that $m(s, u, \cdot)$ increases with $v$ and that $m\left(s^{\prime}, u, v\right)>m(s, u, v)$. Therefore, if $u$ remains constant while the network size increases from $s$ to $s^{\prime}$, the vacancy rate adjusts by decreasing. As a result, the Beveridge curve shifts downwards in the plane $(u, v)$. With a similar reasoning, if $s^{\prime}>s \geq \bar{s}$, the Beveridge curve shifts upwards in the plane $(u, v)$. Let now $(u, v)$ satisfy (16), that is,

$$
y_{1}=\frac{\gamma}{1-\beta}\left[\frac{r+\delta}{(1-\delta) f(s, u, v)}+\beta \frac{v}{u}\right]
$$

Recall that this equation corresponds to the labor demand curve (8) in which the wage has been replaced by (12). We have

$$
\frac{d v}{d s}=-\frac{\frac{r+\delta}{(1-\delta) \dot{f}(s, u, v)^{2}} \frac{\partial f(s, u, v)}{\partial s}}{\frac{r+\delta}{(1-\delta) \dot{f}(s, u, v)^{2}} \frac{\partial f(s, u, v)}{\partial v}-\frac{\beta}{u}}
$$

and Lemma 2 implies that the curve with equation (16) shifts upwards in the plane $(u, v)$ when the network size increases from $s$ to $s^{\prime}$ if $\bar{s} \geq s^{\prime}>s$, while it shifts downwards if $s^{\prime}>s \geq \bar{s}$. Therefore, geometrically, $u^{*}\left(s^{\prime}\right)<u(s)$ if $\bar{s} \geq s^{\prime}>s$, while $u^{*}\left(s^{\prime}\right)>u(s)$ if $s^{\prime}>s \geq \bar{s}$.

\section{Proof of Proposition 5.}

For all $t=1, \ldots,+\infty$, write $(13)$ as $u_{t}=\phi\left(u_{t-1}, v_{t}\right)$, where

$$
\phi\left(u_{t-1}, v_{t}\right)=u_{t-1}\left[1-\delta-h\left(s, u_{t-1}, v_{t}\right)\right]+\delta
$$

Let

$$
\Omega\left(u_{t-1}, v_{t}\right)=b u_{t-1}\left[1-h\left(s, u_{t-1}, v_{t}\right)\right]+y_{1}\left(1-u_{t-1}\right)+y_{0} u_{t-1} h\left(s, u_{t-1}, v_{t}\right)-\gamma v_{t}
$$

The planner's problem is

$$
\max _{\left\{v_{t}\right\}_{t=1}^{+\infty}} \sum_{t=1}^{+\infty} \frac{1}{(1+r)^{t}} \Omega\left(u_{t-1}, v_{t}\right) \text { subject to } u_{t}=\phi\left(u_{t-1}, v_{t}\right), t=1, \ldots,+\infty
$$

The Euler equations are:

$$
\frac{1}{(1+r)^{t}} \frac{\partial \Omega\left(u_{t-1}, v_{t}\right)}{\partial v_{t}}+\frac{1}{(1+r)^{t+1}} \frac{\partial \Omega\left(u_{t}, v_{t+1}\right)}{\partial u_{t}} \frac{\partial u_{t}}{\partial v_{t}}=0, t=1, \ldots,+\infty
$$


where $u_{t}=\phi\left(u_{t-1}, v_{t}\right)$. Since $y_{0}=b=0$, at the steady-state, this simplifies to ${ }^{26}$

$$
y_{1} \frac{\partial m(s, u, v)}{\partial v}=\gamma \frac{1+r}{1-\delta}
$$

In order to see if the private and social solutions coincide, we compare (16) and (20). After some algebra and using the fact that $f(s, u, v)=m(s, u, v) / u$ and $h(s, u, v)=m(s, u, v) / v$, we obtain (19).

\footnotetext{
${ }^{26}$ We use the fact that

$$
\frac{\partial h(s, u, v)}{\partial v}=\frac{\partial[m(s, u, v) / u]}{\partial v}=\frac{1}{u} \frac{\partial m(s, u, v)}{\partial v}
$$
}




\section{IZA Discussion Papers}

\begin{tabular}{|c|c|c|c|c|}
\hline No. & Author(s) & Title & Area & Date \\
\hline 756 & $\begin{array}{l}\text { N. Datta Gupta } \\
\text { R. Oaxaca } \\
\text { N. Smith }\end{array}$ & $\begin{array}{l}\text { Swimming Upstream, Floating Downstream: } \\
\text { Comparing Women's Relative Wage Positions in } \\
\text { the U.S. and Denmark }\end{array}$ & 5 & $04 / 03$ \\
\hline 757 & J. Hunt & Teen Births Keep American Crime High & 5 & $04 / 03$ \\
\hline 758 & $\begin{array}{l}\text { J. Lise } \\
\text { S. Seitz } \\
\text { J. Smith }\end{array}$ & $\begin{array}{l}\text { Equilibrium Policy Experiments and the } \\
\text { Evaluation of Social Programs }\end{array}$ & 6 & $04 / 03$ \\
\hline 759 & E. P. Lazear & The Peter Principle: A Theory of Decline & 1 & $04 / 03$ \\
\hline 760 & E. P. Lazear & Entrepreneurship & 5 & $04 / 03$ \\
\hline 761 & E. P. Lazear & $\begin{array}{l}\text { Output-Based Pay: Incentives, Retention or } \\
\text { Sorting? }\end{array}$ & 5 & $04 / 03$ \\
\hline 762 & $\begin{array}{l}\text { M. Gerfin } \\
\text { R. E. Leu }\end{array}$ & $\begin{array}{l}\text { The Impact of In-Work Benefits on Poverty and } \\
\text { Household Labour Supply - A Simulation Study } \\
\text { for Switzerland }\end{array}$ & 3 & $04 / 03$ \\
\hline 763 & $\begin{array}{l}\text { M. Biewen } \\
\text { S. P. Jenkins }\end{array}$ & $\begin{array}{l}\text { Estimation of Generalized Entropy and Atkinson } \\
\text { Inequality Indices from Complex Survey Data }\end{array}$ & 5 & $04 / 03$ \\
\hline 764 & P. A. Puhani & $\begin{array}{l}\text { A Test of the 'Krugman Hypothesis' for the } \\
\text { United States, Britain, and Western Germany }\end{array}$ & 2 & $04 / 03$ \\
\hline 765 & W. Schnedler & $\begin{array}{l}\text { On the Prudence of Rewarding A While Hoping } \\
\text { for B }\end{array}$ & 5 & $04 / 03$ \\
\hline 766 & $\begin{array}{l}\text { D. N. F. Bell } \\
\text { R. A. Hart }\end{array}$ & $\begin{array}{l}\text { How Important Is Guaranteed or Institutionalised } \\
\text { Overtime? }\end{array}$ & 5 & $04 / 03$ \\
\hline 767 & $\begin{array}{l}\text { P. Carneiro } \\
\text { K. T. Hansen } \\
\text { J. J. Heckman }\end{array}$ & $\begin{array}{l}\text { Estimating Distributions of Treatment Effects } \\
\text { with an Application to the Returns to Schooling } \\
\text { and Measurement of the Effects of Uncertainty } \\
\text { on College Choice }\end{array}$ & 6 & $04 / 03$ \\
\hline 768 & $\begin{array}{l}\text { J. J. Heckman } \\
\text { S. Navarro-Lozano }\end{array}$ & $\begin{array}{l}\text { Using Matching, Instrumental Variables and } \\
\text { Control Functions to Estimate Economic Choice } \\
\text { Models }\end{array}$ & 6 & $04 / 03$ \\
\hline 769 & $\begin{array}{l}\text { L. Flood } \\
\text { J. Hansen } \\
\text { R. Wahlberg }\end{array}$ & $\begin{array}{l}\text { Household Labor Supply and Welfare } \\
\text { Participation in Sweden }\end{array}$ & 3 & $04 / 03$ \\
\hline 770 & A. Heitmueller & Coordination Failures in Network Migration & 1 & $04 / 03$ \\
\hline 771 & $\begin{array}{l}\text { A. Calvó-Armengol } \\
\text { Y. Zenou }\end{array}$ & $\begin{array}{l}\text { Job Matching, Social Network and } \\
\text { Word-of-Mouth Communication }\end{array}$ & 5 & $05 / 03$ \\
\hline
\end{tabular}

An updated list of IZA Discussion Papers is available on the center's homepage www.iza.org. 